\title{
Article \\ Production of Microfibrillated Cellulose from Fast-Growing Poplar and Olive Tree Pruning by Physical Pretreatment
}

\author{
David Ibarra $^{1}{ }^{1}$, Raquel Martín-Sampedro ${ }^{1}{ }^{(\mathbb{C}}$, Bernd Wicklein $^{2}$, Úrsula Fillat $^{1}$ and María E. Eugenio ${ }^{1, *}$ \\ 1 Forest Research Center (INIA, CSIC), Ctra. de la Coruña Km 7.5, 28040 Madrid, Spain; \\ ibarra.david@inia.es (D.I.); raquel.martin@inia.es (R.M.-S.); fillat.ursula@inia.es (Ú.F.) \\ 2 Materials Science Institute of Madrid (ICMM-CSIC), Sor Juana Inés de la Cruz 3, Cantoblanco, \\ 28049 Madrid, Spain; bernd@icmm.csic.es \\ * Correspondence: mariaeugenia@inia.es; Tel.: +34-913473948
}

Citation: Ibarra, D.

Martín-Sampedro, R.; Wicklein, B.; Fillat, Ú.; Eugenio, M.E. Production of Microfibrillated Cellulose from Fast-Growing Poplar and Olive Tree Pruning by Physical Pretreatment. Appl. Sci. 2021, 11, 6445. https:// doi.org/10.3390/app11146445

Academic Editor: Kwang Ho Kim

Received: 17 June 2021

Accepted: 9 July 2021

Published: 13 July 2021

Publisher's Note: MDPI stays neutral with regard to jurisdictional claims in published maps and institutional affiliations.

Copyright: (c) 2021 by the authors. Licensee MDPI, Basel, Switzerland. This article is an open access article distributed under the terms and conditions of the Creative Commons Attribution (CC BY) license (https:/ / creativecommons.org/licenses/by/ $4.0 /)$.

\begin{abstract}
Motivated by the negative impact of fossil fuel consumption on the environment, the need arises to produce materials and energy from renewable sources. Cellulose, the main biopolymer on Earth, plays a key role in this context, serving as a platform for the development of biofuels, chemicals and novel materials. Among the latter, micro- and nanocellulose have been receiving increasing attention in the last few years. Their many attractive properties, i.e., thermal stability, high mechanical resistance, barrier properties, lightweight, optical transparency and ease of chemical modification, allow their use in a wide range of applications, such as Paper or polymer reinforcement, Packaging, construction, membranes, bioplastics, bioengineering, optics and electronics. In view of the increasing demand for traditional wood pulp (e.g., obtained from eucalypt, birch, pine, spruce) for micro/nanocellulose production, dedicated crops and agricultural residues can be interesting as raw materials for this purpose. This work aims at achieving microfibrillated cellulose production from fast-growing poplar and olive tree pruning using physical pretreatment (PFI refining) before the microfibrillation stage. Both raw materials yielded microfibrillated cellulose with similar properties to that obtained from a commercial industrial eucalypt pulp, producing films with high mechanical properties and low wettability. According to these properties, different applications for cellulose microfibers suspensions and films are discussed.
\end{abstract}

Keywords: cellulose microfibers; fast-growing poplar; films; mechanical properties; olive tree pruning; optical properties; physical pretreatment; wetting properties

\section{Introduction}

The social and environmental challenges resulting from the widespread consumption of fossil fuels are driving research efforts to solve the current societal problems. The general strategy is to make the bioeconomy concept a reality through the efficient usage of renewable resources in the sustainable production of chemicals, materials and energy [1]. This scenario has led to a growing interest in the design and development of different products from cellulose [2].

Cellulose is the most abundant natural polymer on Earth, where it exists as a structural component in the cell walls of plants and some marine animals, algae and fungi, as well as biofilms produced by bacteria [3]. It is a very promising polymer due to its specific properties, i.e., renewably sourced, biodegradable, biocompatible and easily modified or functionalized, which make cellulose a material with great potential for applications in different technologies and in a wide range of products. Although this biopolymer is currently used in different industrial sectors such as pulp and Paper, textiles and pharmaceuticals, among others, its structural and chemical versatility opens the door to applications in different industrial sectors (packaging, construction, separation membranes, bioplastics, bioengineering and optoelectronics) [2]. Nevertheless, in order to meet the specific requirements for these new applications, it is necessary to use cellulose at the micro/nano-scale [4], 
resulting in unique mechanical, optical, barrier, thermal and rheological properties that far exceed those of raw cellulose.

Nanocellulose refers to long and entangled cellulose nanofibers (CNFs), as well as crystalline rod-like cellulose nanocrystals (CNCs). Regarding CNFs, their production generally encompasses two different steps, using chemical pulp fibers as the raw material [2]. Firstly, a pretreatment step is necessary to reduce fiber length, increase external fibrillation and separate fiber bundles, as well as to introduce highly charged functional groups to the fibers or to modify their chemical composition and degree of crystallinity [5]. Secondly, a nanofibrillation step using equipment such as high-pressure homogenizers or microfluidizers is necessary to further reduce the fiber length and longitudinally fibrillate the fibers to nanometer-sized diameters [4]. Unfortunately, this process consumes a lot of energy. Therefore, to achieve energy savings, it might be sufficient for some applications to reach only microscale diameters in the fibers during fibrillation [6]. The pretreatment step also contributes to avoid not only excessive energy consumption but also processability restrictions [4]. Different pretreatment technologies have been reported [4,5,7,8], including physical (mechanical refining by PFI mills, disc refiners, Valley beaters), chemical (2,2,6,6-tetramethylpiperidine 1-oxyl radical (TEMPO)-mediated oxidation, cationization, carboxymethylation) and biological (enzymatic hydrolysis) pretreatments. Regarding mechanical refining, a dilute pulp fiber suspension is forced through a gap between the rotor and stator discs. These discs have surfaces fitted with bars and grooves against which the fibers are subjected to repeated cyclic stresses, producing profound changes in morphology and size of the pulp fibers and, consequently, being more exposed to fibrillation during the microfluidization step [9].

As commented above, nanocellulose is typically obtained from chemical pulp fibers, using traditional woody species either from hardwoods (e.g., eucalypt, aspen and birch) or softwoods (e.g., pine, spruce and fir) $[7,10,11]$. In addition to these woody species, dedicated crops and agricultural residues may be interesting and attractive raw materials for nanocellulose production [4]. Among dedicated woody crops, the Salicaceae family (poplars and willows) has gained special significance due to their high growth rate, high biomass accumulation and quality, showing high resistance to pests and diseases, tolerance to salinity and adaptation to water and fertilizer limitations. The suitability of many of these species and their hybrids for biomass production is widely supported in different cultivation areas $[12,13]$ and specifically in the Mediterranean area [14]. On the other hand, one of the most abundant and cheapest lignocellulosic residues generated in Mediterranean countries is olive tree pruning. This agricultural residue represents an estimated average production of $3000 \mathrm{~kg} / \mathrm{ha}$ per year worldwide [15]. Olive tree pruning is usually eliminated to keep fields clean and to prevent the spread of plant diseases by burning, grinding or spreading onto fields, causing economic costs and environmental impact. The cellulosic fraction from both materials, poplar and olive tree pruning, has already been widely evaluated for producing fermentable sugars, bioethanol and chemical pulps [16-19]. However, only a few works have been published regarding their use as a raw material for micro/nanocellulose production [20-22], requiring further studies for this purpose.

Taking into account the above, this work shows the use of fast-growing poplar and olive tree pruning raw materials as a source for microfibrillated cellulose (MFC) production by mechanical refining (PFI refining) and subsequent defibrillation in a high-pressure microfluidizer.The resulting MFC samples were characterized in terms of chemical composition, polymerization degree, nanofibrillation yield and water retention value. Moreover, techniques such as X-ray diffraction (XRD) and scanning electron microscopy (SEM) were also used to evaluate crystallinity and fiber morphology, respectively. Finally, MFC films were produced and their mechanical and optical properties and wettability were analyzed. All results were compared with a MFC reference material obtained from a commercial bleached eucalypt kraft pulp following the same MFC production procedure. 


\section{Materials and Methods}

\subsection{Raw Materials and Chemicals}

Olive tree (Olea europaea) pruning (OTP) residue was kindly supplied by the Universidad de Jaén (Spain). An autochthonous clone of poplar (Populus alba L.) from the Guadalquivir valley, PO-10-10-20, was kindly provided by Silviculture and Forest Management Department of INIA, CSIC (Madrid, Spain). This poplar clone was grown in plantations aiming at the production of biomass in the central area of Spain $\left(40^{\circ} 28^{\prime} \mathrm{N}\right.$, $3^{\circ} 22^{\prime} \mathrm{W}$, and $595 \mathrm{~m}$ above sea level). The plantation was cut in the third year (first rotation), and wood samples were collected, chipped, homogenized, and stored until used. Commercial bleached Eucalyptus globulus kraft pulp from La Montañanesa (Grupo Torraspapel, Zaragoza, Spain) was used as a source for the production of the reference MFC. All chemicals were reagent-grade and purchased from Panreac (Barcelona, Spain) or Sigma-Aldrich (Madrid, Spain).

\subsection{Pulp Production}

Kraft pulping of both materials was carried out in a cylindrical $15 \mathrm{~L}$ batch reactor with a jacket-type electrical heater controlled by a computer. The reactor was fitted with a rotating axle to ensure proper agitation. OTP was cooked under the following conditions: $175{ }^{\circ} \mathrm{C}, 90 \mathrm{~min}, 20 \%$ active alkali, $25 \%$ sulfidity and 5:1 liquid/solid ratio, according to Fillat et al. [20]; whereas for poplar: $170{ }^{\circ} \mathrm{C}, 120 \mathrm{~min}, 17 \%$ active alkali, $20 \%$ sulfidity, and 7:1 liquid/solid ratio, according to Kang et al. [23]. The resulting cooked materials were fiberized in a wet disintegrator at 30,000 rpm for $30 \mathrm{~min}$ and Particles were separated by sieving through a screen of $0.16 \mathrm{~mm}$ mesh.

After kraft pulping, OTP pulp was subjected to an oxygen delignification $(\mathrm{O})$ stage followed by a peroxide bleaching $(\mathrm{P})$ stage [20]. The conditions of the $\mathrm{O}$ stage were $100{ }^{\circ} \mathrm{C}$, $50 \mathrm{~min}, 6 \mathrm{MPa}$ of oxygen pressure, $2.5 \% \mathrm{NaOH}$ o.d.p. (oven dry pulp), $0.5 \% \mathrm{MgSO}_{4}$ o.d.p., $0.1 \%$ diethylenetriaminepentaacetic acid (DTPA) o.d.p. and $10 \%(w / v)$ of consistency, using the same reactor described above for pulping process. After oxygen delignification, OTP pulp was bleached using a P stage at the following conditions: $90^{\circ} \mathrm{C}, 90 \mathrm{~min}, 1.5 \%$ $\mathrm{NaOH}$ o.d.p., $0.2 \% \mathrm{MgSO}_{4}$ o.d.p., $1 \%$ DTPA o.d.p. and $3 \% \mathrm{H}_{2} \mathrm{O}_{2}$ o.d.p. and $6 \%(w / v)$ of consistency in a plastic bag submerged in a thermostatic bath. Three consecutive $\mathrm{P}$ bleaching stages were performed, resulting in the OPPP bleaching sequence (one stage of oxygen (O) followed by three consecutive stages using hydrogen peroxide (PPP)). Pulp samples were washed after each stage using deionized water and stored at $4{ }^{\circ} \mathrm{C}$.

On the other hand, a standard industrial TCF (totally chlorine free) bleaching sequence consisting of OOQPoP was carried out over the unbleached poplar kraft pulp, where O was a delignification stage of oxygen (held twice), $\mathrm{Q}$ a chelating stage and $\mathrm{PoP}$ a hydrogen peroxide bleaching stage with or without oxygen, respectively [24]. The conditions of both oxygen delignification stages were: $6 \mathrm{MPa}$ of oxygen pressure, $60 \mathrm{~min}, 98^{\circ} \mathrm{C}, 0.5 \% \mathrm{MgSO}_{4}$ o.d.p. (oven dry pulp), $1.5 \% \mathrm{NaOH}$ o.d.p., and $20 \%(w / v)$ of consistency. The chelating step was performed using $0.3 \%$ DTPA at $85^{\circ} \mathrm{C}$ for $60 \mathrm{~min}$ (pH 5-6). Finally, the bleaching conditions in the first step were: $2 \% \mathrm{NaOH}, 0.5 \% \mathrm{Na}_{2} \mathrm{Si}_{2} \mathrm{O}_{3}, 0.1 \% \mathrm{MgSO}_{4}$ and $3 \% \mathrm{H}_{2} \mathrm{O}_{2}$ for $140 \mathrm{~min}$ at $105^{\circ} \mathrm{C}$ pressurized with oxygen at $6 \mathrm{~kg} \mathrm{~cm}^{-2}$, while the second step was carried out using the same chemical reagents but for $180 \mathrm{~min}$ at $98{ }^{\circ} \mathrm{C}$ without pressure. Pulps samples were washed after each stage using deionized water and stored at $4{ }^{\circ} \mathrm{C}$.

OTP, poplar and commercial eucalypt bleached kraft pulps were characterized according to the corresponding standards.

\subsection{PFI Refining}

Never-dried bleached kraft pulps (45 g o.d.p.) were first soaked for demineralization in a dilute $\mathrm{HCl}$ solution at $\mathrm{pH} 2,10 \%(w / v)$ consistency and room temperature for $20 \mathrm{~min}$ with mechanical agitation. After filtration and washing with deionized water, fibers were changed to their sodium form to enhance the fibrillation efficiency $[25,26]$. For that, cellulose fibers were suspended in $5 \mathrm{mM} \mathrm{NaHCO}_{3}$ and $\mathrm{NaOH}$ was added to reach $\mathrm{pH}$ 8-9; 
the pulp was stirred for $20 \mathrm{~min}$ at room temperature and rinsed with deionized water until the filtrate conductivity was below $20 \mu \mathrm{S} \mathrm{cm}{ }^{-1}$. After this, 30 g o.d.p. of each exchanged pulp was disintegrated in $2 \mathrm{~L}$ water (30,000 revolutions). Then, the consistency was adjusted to $10 \%(w / v)$ and the pulp was refined in a PFI mill until $90^{\circ} \mathrm{SR}$ (Schopper Riegler degree).

\subsection{Microfluidization}

Never-dried refined pulps were processed in a high pressure microfluidizer (Microfluidizer M-110EH, Microfluidics Corp., Westwood, MA, USA) with 100 and $200 \mu \mathrm{m}$ interaction chambers. The smaller the chamber size, the higher the degree of defibrillation [27]. The $2 \%$ $(w / v)$ fiber suspensions were Passed six times through the high pressure microfluidizer (1st to 3rd Pass: chamber of $200 \mu \mathrm{m}$ at 1600 bar; 4th to 6th Pass: sequential chambers of 200 and $100 \mu \mathrm{m}$ at $1900 \mathrm{bar}$ ). Microfibrillated cellulose obtained from eucalypt pulp (referenced as E-MFC), poplar pulp (P-MFC) and OTP pulp (O-MFC) were stored at $4{ }^{\circ} \mathrm{C}$.

\subsection{Pulps and MFCs Characterization}

\subsubsection{Chemical Composition}

The chemical composition of the raw materials and their corresponding bleached pulps was determined using the Laboratory Analytical Procedures (LAP) for biomass analysis provided by the National Renewable Energies Laboratory [28]. The solid residue remaining after acid hydrolysis is referred to as acid insoluble lignin (Klason lignin). The carbohydrate content was quantified by high-performance liquid chromatography (HPLC) in an Agilent Technologies 1260 HPLC fitted with a refractive index detector (Agilent, Waldbronn, Germany), using an Agilent Hi-PlexPb column operated at $70{ }^{\circ} \mathrm{C}$ with ultrapure water as a mobile-phase pumped at a rate of $0.6 \mathrm{~mL} \mathrm{~min}{ }^{-1}$.

\subsubsection{Viscosity}

Viscosity was measured following ISO 5351-2 standard using cupriethylenediamine (CED) solution. The degree of polymerization (DPv) was calculated according to the Mark-Houwink Equation (1):

$$
\mu=\mathrm{Kp} \cdot \mathrm{DPv}^{\mathrm{a}},
$$

where $\mu$ is the intrinsic viscosity and $\mathrm{Kp}$ and a are Parameters that depend on the Particular polymer-solvent system. For CED and cellulose, $\mathrm{Kp}$ and a are $1.70 \mathrm{~mL} \mathrm{~g}^{-1}$ and 0.80 , respectively [29].

\subsubsection{Fibrillation Yield}

MFC samples were diluted to $0.1 \%(w / v)$. Then, diluted samples were centrifuged (4500 rpm, $20 \mathrm{~min}$ ) in order to separate nanofibrillated material (in supernatant) from non-fibrillated and Partially fibrillated fibers (in sediment) [30]. The sediment was then dried $\left(104{ }^{\circ} \mathrm{C}\right)$. Finally, fibrillation yields were calculated as the relation between the mass of cellulose nanofibers in the supernatant (calculated by subtraction) and the mass of centrifuged cellulose according to Equation (2).

$$
\text { Fibrillation yield }(\%)=100 \cdot(\mathrm{WT}-\mathrm{WS}) / \mathrm{WT} \text {, }
$$

where WT is the dry weight of micro-nanofibers in the CNF suspensions before centrifugation and WS is the dry sediment after centrifugation.

\subsubsection{Water Retention Value}

The water retention value (WRV) of the MFC samples was evaluated according to Chen et al. [31] but with an acetate filter of $0.45 \mu \mathrm{m}$ pore size. MFC samples were 
centrifuged $(3000 \times g, 20 \mathrm{~min}$, at room temperature). The water retention value was calculated using Equation (3):

$$
\mathrm{WRV}(\%)=100 \cdot(\mathrm{Ww}-\mathrm{Wd}) / \mathrm{Wd},
$$

where $\mathrm{Ww}$ is the weight of the wet sample remaining in the filter after centrifugation $(g)$ and $\mathrm{Wd}$ is the weight of the dry sample remaining in the filter after centrifugation dried in an oven at $105^{\circ} \mathrm{C}$ until constant weight (g o.d.p.).

\subsubsection{X-ray Diffraction Analysis (XRD)}

The crystallinity of the fibers in pulps and MFC samples was analyzed by powder X-ray diffraction (XRD) using a Bruker D8 Advance instrument (Bruker, Billerica, MA, USA) equipped with a $\mathrm{Cu}$ anode ( $\mathrm{CuK} \alpha$ radiation) and a Ni filter. For this analysis, the samples were pressed as pellets. The crystallinity index (CI) was calculated by the Segal method as seen in Equation (4)

$$
\mathrm{CI}=\left(\mathrm{I}_{200}-\mathrm{I}_{\mathrm{AM}}\right) / \mathrm{I}_{002} \cdot 100
$$

where $\mathrm{I}_{002}$ is the intensity of the (002) reflection and $\mathrm{I}_{\mathrm{AM}}$ is the intensity attributed to the amorphous phase at approximately $2 \Theta=18.5^{\circ}$.

The crystallite size $t$ was calculated according to the Scherrer equation using the (002) reflection:

$$
\mathrm{t}=(\mathrm{k} \cdot \lambda) /(\beta \cdot \cos \Theta)
$$

where $\mathrm{k}$ is the correction factor $(0.9), \lambda$ is the radiation wavelength $(0.15418 \mathrm{~nm}), \beta$ is the width of the peak at the half of maximum height (in radians), and $\theta$ is the diffraction angle of the peak.

\subsubsection{Scanning Electron Microscopy (SEM)}

The morphology of the MFCs was characterized using a field emission scanning electron microscope (FE-SEM) from FEI (NOVA NanoSEM 230) and Philips (XL30 S-FEG). For SEM observation, the samples were freeze-dried and transferred onto sticky carbon conductive tape followed by metallization through $\mathrm{Au}$ and $\mathrm{Cr}$ sputtering, respectively.

\subsection{Film Preparation}

MFC samples (2.4 g o.d.p) were disintegrated in water $(1500 \mathrm{~mL})$ (30,000 revolutions). The MFC films were obtained using the method of rapid Köthen sheet forming of laboratory hand sheets with modifications. A polyamide open mesh fabric screen (Sefar Nitex 03-10/2, mesh opening of $10 \mu \mathrm{m}$, open area of $2 \%$ ) was placed above the wire mesh to prevent fiber loss. The suspensions were drained under vacuum and the obtained films and the fabric screen were hot-pressed for $10 \mathrm{~min}$ at $70^{\circ} \mathrm{C}$.

Mechanical and Optical Properties and Wettability in MFC Films

The thickness and bulk density of the MFC films were determined according to ISO 534 using the Messmer Büchel-Digital Micrometer (Venco S.A, Madrid, Spain). Tensile index and elongation at break were evaluated in a dynamometer DY-20 (Adamel Lhomargy, Roissy-en-Brie, France) according to ISO 5270 (initial grip separation of $100 \pm 2 \mathrm{~mm}$ and crosshead speed of $10 \pm 2.5 \mathrm{~mm} \mathrm{~min}^{-1}$ ). Brightness and opacity were determined using a spectrophotometer ELREPHO 070 (Lorentzen and Wettre) according to ISO 2470 and ISO 2471, respectively.

Wetting properties of the MFC films were assessed by using dynamic water vapor sorption equipment, Aquadyne DVS (Quantachrome Instruments, Boynton Beach, FL, USA). For that, MFC samples $\left(10 \mathrm{mg}\right.$ ) were purged at $80^{\circ} \mathrm{C}$ until the sample weight remained constant. Mass changes due to water adsorption or desorption were recorded at $25{ }^{\circ} \mathrm{C}$ in the relative humidity range of 0 to $95 \%$. 


\section{Results and Discussion}

\subsection{Pulp Production and Characterization}

It is well known that the composition of the lignocellulosic biomass plays an important role in assessing its revalorization, as it has a great influence on the characteristics of the obtained products [32]. Table 1 shows the composition of the raw materials and their corresponding bleached pulps used in this work to produce cellulose microfibers by mechanical means.

Table 1. Chemical composition of raw materials and bleached pulps according to National Renewable Energies Laboratory (NREL). The results represent the averages of three replicates and its standard deviation.

\begin{tabular}{cccccc}
\hline & $\begin{array}{c}\text { Extractives } \\
\text { (\% o.d.p.) }\end{array}$ & $\begin{array}{c}\text { Klason Lignin } \\
\text { (\% o.d.p.) }\end{array}$ & $\begin{array}{c}\text { Soluble Lignin } \\
\text { (\% o.d.p.) }\end{array}$ & $\begin{array}{c}\text { Glucan } \\
\text { (\% o.d.p.) }\end{array}$ & $\begin{array}{c}\text { Xylan } \\
\text { (\% o.d.p.) }\end{array}$ \\
\hline O & $7.1 \pm 0.4$ & $22.0 \pm 0.4$ & $3.7 \pm 0.7$ & $36.8 \pm 0.4$ & $21.9 \pm 0.6$ \\
P & - & $18.9 \pm 0.2$ & $3.9 \pm 0.1$ & $36.3 \pm 0.4$ & $20.5 \pm 0.1$ \\
E & $5.3 \pm 0.3$ & $27.1 \pm 0.5$ & $2.0 \pm 0.3$ & $45.1 \pm 0.6$ & $17.4 \pm 0.5$ \\
O-Pulp & $0.6 \pm 0.1$ & $0.7 \pm 0.0$ & $0.9 \pm 0.0$ & $70.5 \pm 3.1$ & $23.6 \pm 1.0$ \\
P-Pulp & - & $0.8 \pm 0.6$ & $0.4 \pm 0.3$ & $74.0 \pm 2.1$ & $24.0 \pm 1.9$ \\
E-Pulp & $0.4 \pm 0.1$ & $0.5 \pm 0.3$ & $0.9 \pm 0.6$ & $76.1 \pm 2.7$ & $19.1 \pm 0.7$ \\
\hline
\end{tabular}

O: olive tree pruning; P: poplar; E: eucalypt; O-Pulp: olive pulp; P-Pulp: poplar pulp; E-Pulp: eucalypt pulp.

The composition of the used materials shows typical hardwood values $[16,22,33]$ and is more similar between poplar and olive.

Several authors have studied the effect of hemicellulose and lignin content on the nanofibrillation process to obtain cellulose micro/nanofibers. For instance, Chaker et al. [34] observed the highest efficiency in the nanofibrillation process when the hemicellulose content of the starting material was about $25 \%$. The same authors concluded that halving the hemicellulose content also halved the efficiency of fibrillation. The reason for this effect is that hemicelluloses (mainly xylans) stabilizes the aqueous suspension of the fibers, preventing the aggregation of the microfibrils and thus, favoring the fibrillation process [35].

On the other hand, it has been observed by other authors that when the starting material contains more than approximately $20 \%$ of lignin, the efficiency of the fibrillation process decreases [36]. Nonetheless, excessive delignification has also been shown to decrease the fibrillation process [37]. Therefore, it seems that a residual amount of lignin in the starting material could increase the efficiency of the fibrillation process, as the antioxidant capacity of such residual lignin could prevent the re-bonding of formerly fractured covalent bonds [38].

In view of the above, a kraft pulping process was applied to reduce the lignin content and increase the glucan amount without eliminating the hemicellulose content of the raw materials, thus encouraging the subsequent fibrillation process to obtain cellulose micro/nanofibers. After applying the kraft pulping process, an almost complete elimination of extractives, a decrease in lignin content (resulting in a total residual lignin content of around $1.2-1.7 \%$ ) and an increase in carbohydrates (more pronounced for glucan (increase of $68-103 \%$ ) than for xylan (increase of 7-17\%) were observed in all cases. The hemicellulose contents obtained in the resulting bleached kraft pulps were $23.6 \%$ and $24 \%$ for O-Pulp and P-Pulp, respectively. These values are very close to the optimum content to ensure the efficiency of the nanofibrillation process, as mentioned above. However, the E-pulp (reference sample) showed a slightly lower value (19.1\%). In general, these hemicellulose content values are similar to or even higher than those observed by other authors for pulps used to successfully obtain nanofibrillated cellulose from different raw materials $[20,22,39]$.

On the other hand, the cellulose content observed in this work was higher than those reported by other studies using eucalypt and olive tree pruning for cellulose nanofibers, which could improve, in our case, the yield of the microfibrillated cellulose production $[20,22]$. 


\subsection{MFC Characterization}

\subsubsection{Scanning Electron Microscopy (SEM)}

Figure 1 shows SEM images of MFC obtained from the three different pulps. In general, a high amount of nanofibrillated fibers between 20 and $150 \mathrm{~nm}$ in thickness was observed in all samples. However, some non-fibrillated fibers of a few hundred nanometers thickness are also observable, as well as non-fibrillated fibers in Patchworks.

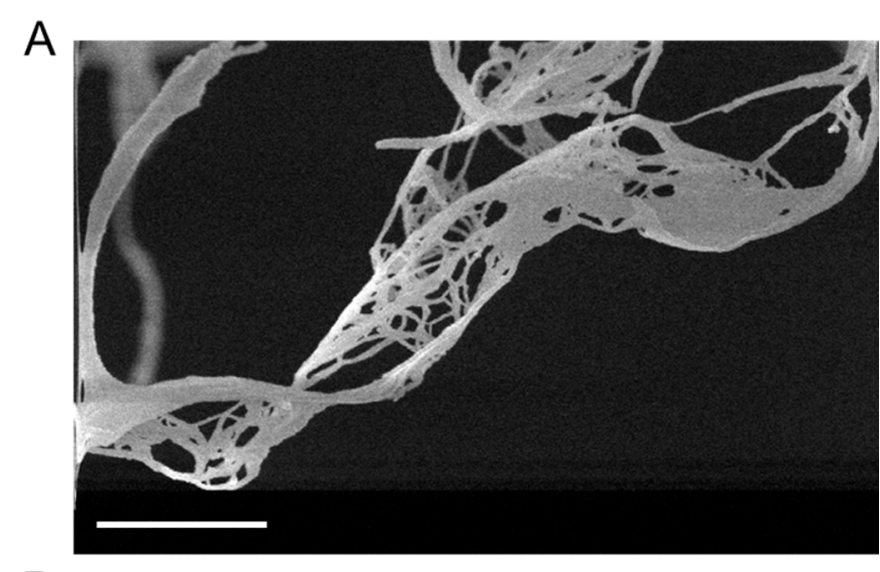

B
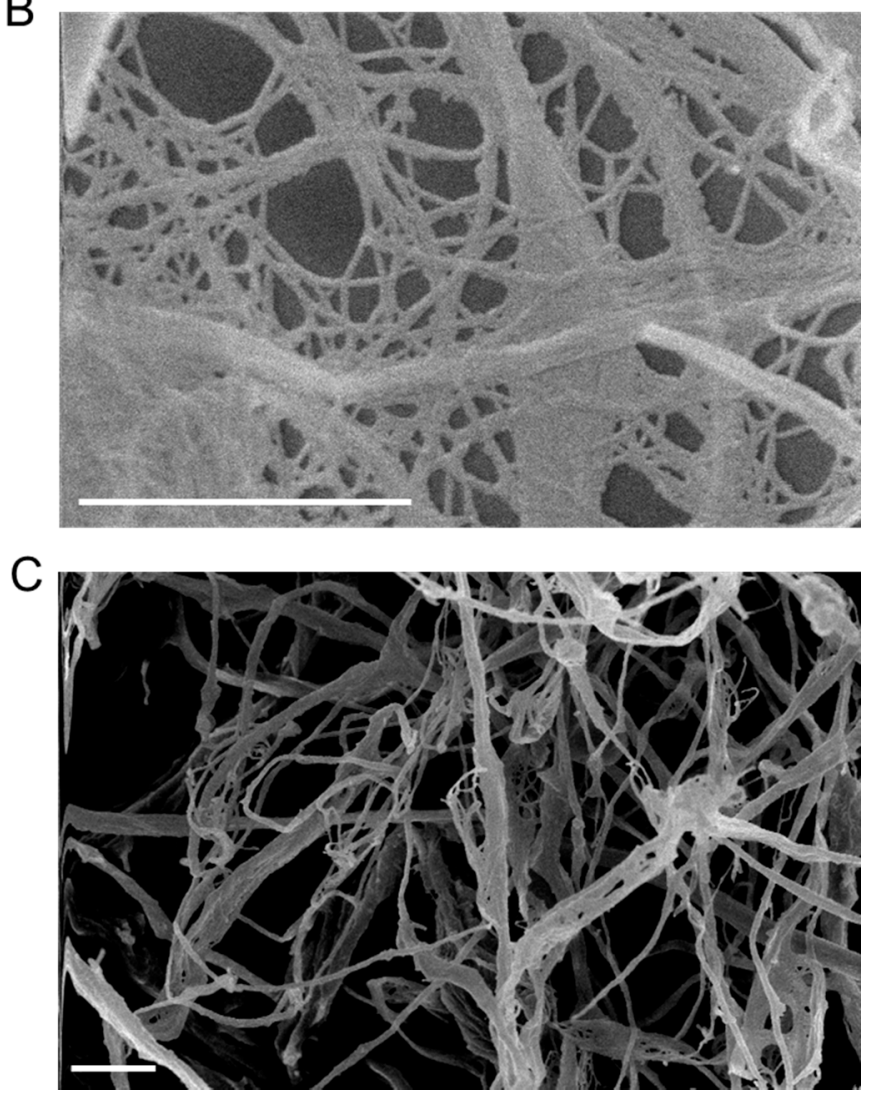

Figure 1. SEM images of O-MFC (A), P-MFC (B) and E-MFC (C), respectively. The scale bars refer to $1 \mu \mathrm{m}$.

\subsubsection{Degree of Polymerization}

Degree of polymerization (DP) is a Parameter associated, to some extent, with the length of the microfibers. Table 2 shows a decrease in DP for the three MFC samples (decrease values of $63 \%$ for olive tree pruning, $47 \%$ for poplar and $39 \%$ for eucalypt) after PFI refining followed by microfluidization. This decay is mainly attributed to the cutting of cellulose fibrils produced by the high shear forces reached during the refining pretreatment 
and microfluidization. Solala et al. [40] also described a DP decrease when different birch kraft pulps (unbleached, oxygen delignified and bleached) were refined with a Masuko equipment, observing different DP decrease values depending on the used pulps ( $36.5 \%$ for unbleached pulp, $34.4 \%$ for oxygen delignified pulp and 19\% for bleached pulp). In the same way, Espinosa et al. [32] observed a similar decrease (55\%) when orange tree pruning unbleached pulp was subjected to PFI milling (until reaching a Schopper-Riegler degree value of 90) followed by high-pressure homogenization treatment (four times at 300 bar, three times at 600 bar and three times at 900 bar). In the same study, Espinosa et al. [32] also described a slightly higher DP decrease (63\%) using TEMPO oxidation pretreatment instead of PFI refining. In this case, in addition to the shortening of cellulose fibrils produced by the shear forces during microfluidization, the TEMPO reaction produced a slight cellulose degradation (mainly amorphous cellulose) into gluconic acid and small fragments by different chemical mechanisms [20].

Table 2. Degree of polymerization of the different pulps and their corresponding MFCs.

\begin{tabular}{lc}
\hline & Degree of Polymerization \\
\hline O-Pulp & $2742 \pm 52$ \\
P-Pulp & $2076 \pm 51$ \\
E-Pulp & $2129 \pm 43$ \\
O-MFC & $1010 \pm 69$ \\
P-MFC & $1100 \pm 60$ \\
E-MFC & $1290 \pm 26$ \\
\hline
\end{tabular}

O-Pulp: olive pulp; P-Pulp: poplar pulp; E-Pulp: eucalypt pulp; O-MFC: olive microfibrillated cellulose; P-MFC: poplar microfibrillated cellulose; E-MFC: eucalypt microfibrillated cellulose.

\subsubsection{Nanofibrillation Yield and Water Retention Value (WRV)}

MFCs obtained by mechanical treatments consist of a mixture of fibers, fiber fragments, fines and fibrils [41] that create an inhomogeneous material [42]. The nanofiber content is assessed by centrifugation of a dilute suspension of cellulose micro/nanofibers, where nanofibers remain suspended, whereas fibers and microfibrillated material precipitate. The nanofibrillation yields in this work ranged from $11.3 \%$ to $13.3 \%$ (Table 3), indicating that the samples contain a significant amount of fibers and microfibers, in agreement with SEM observations. These values are lower than those observed by Jiménez-López et al. [43] and Delgado-Aguilar et al. [44]. However, these authors used different raw materials (elm) or more intensive mechanical treatment conditions to produce CNFs. Other authors, such as Espinosa et al. [32], showed similar nanofibrillation yields when employing olive tree pruning to produce MFC by exclusively mechanical means, although they used more severe conditions in the fibrillation process than those used in this work (10 Passes vs. 6 Passes through the microfluidizer).

Table 3. Nanofibrillation yield (\%) and water retention value (\%) of MFCs.

\begin{tabular}{lcc}
\hline & $\begin{array}{c}\text { Nanofibrillation Yield } \\
(\mathbf{\%})\end{array}$ & $\begin{array}{c}\text { Water Retention Value } \\
\mathbf{( \% )}\end{array}$ \\
\hline O-Pulp & - & $294 \pm 11$ \\
P-Pulp & - & $230 \pm 12$ \\
E-Pulp & - & $222 \pm 8$ \\
O-MFC & $12.9 \pm 0.3$ & $520 \pm 43$ \\
P-MFC & $13.3 \pm 3.3$ & $499 \pm 39$ \\
E-MFC & $11.3 \pm 0.6$ & $481 \pm 10$
\end{tabular}

O-Pulp: olive pulp; P-Pulp: poplar pulp; E-Pulp: eucalypt pulp; O-MFC: olive microfibrillated cellulose; P-MFC: poplar microfibrillated cellulose; E-MFC: eucalypt microfibrillated cellulose.

The carboxylic acid content is known to enhance the nanofibrillation yield [20]. When cellulose micro/nanofibers are produced using only mechanical processes, as in this case, the carboxylic content does not increase compared to those observed in the starting pulp 
(lower than $90 \mu \mathrm{mol} \mathrm{g}^{-1}$ ), thus explaining the low nanofibrillation yields. On the other hand, the lower nanofibrillation yield observed for E-MFC could be attributed, amongst other factors, to the lower hemicellulose content, since the lignin content was very similar for all samples. Moreover, the nanofibrillation yield depends not only on the raw material (composition, crystallinity, carboxylic acid content, etc.) but also on the type of process used to obtain it. Thus, a more severe nanofibrillation process or other types of pretreatment such as chemical oxidation mediated by TEMPO could be used to increase nanofibrillation yields [20,43].

On the other hand, pulp swelling is connected to the water retention value and it depends on the fibrillation degree and the surface chemistry of fibers [8]. Swelling also depends on the fiber structure, on the degree of crystallinity and on the presence of amorphous and porous regions. The mechanical treatments used during the cellulose microfiber production resulted in an increase in the WVR value for all samples $(77 \%, 117 \%$ and $116 \%$ for O-MFC, P-MFC and E-MFC, respectively). This fact has been attributed mainly to an increase in the specific surface area in the samples [8]. Higher increases have been obtained by other authors [20] also using bleached olive pruning pulp as starting material for cellulose nanofiber production. However, these authors used a chemical pretreatment (TEMPO-mediated oxidation) that subsequently produced a CNF with a higher specific surface area (nanofibrillation yields around $48 \%$ ) and with carboxylate groups on the nanofiber surface, which has higher affinity for water than hydroxyl groups [43,45]. Spence et al. [46] also found higher increases in WRV values in CNFs produced from different raw materials including softwood pulp, hardwood pulp, and thermomechanical pulp, among others, but with a more severe mechanical pre-treatment than that used in this work.

\subsubsection{Crystallinity}

The powder X-ray diffraction (XRD) Pattern of the three MFCs show the typical reflections of crystalline cellulose $\mathrm{I} \beta$ at $2 \theta=22.6^{\circ}$ and $15.8^{\circ}$, which correspond to the (200), (110) and (110) planes, respectively (Figure 2) [47]. The latter two reflections are superimposed. The crystallinity indices, $\mathrm{CI}$, calculated from the diffractograms, were $84 \%$ (P-MFC), 79\% (E-MFC) and 76\% (O-MFC). These values suggest that P-MFC is slightly more crystalline than the other two MFC samples. Thus, although the process used to obtain MFC was the same, crystallinity also depends on the initial raw material [43].

On the other hand, it is well known that nanofibrillation processes can reduce the crystallinity of the resultant cellulose nanofibers [48]. Some authors have explained that this may be due to the breaking of the highly ordered crystalline structure or due to the cellulose nanofibers' hornification during the nanofibrillation process [49]. Herein, the chemomechanical process involving TEMPO-mediated oxidation prior to nanofibrillation is especially prone to Partially damaging the crystalline cellulose structure [20]. For instance, the CI of TEMPO-CNF from eucalypt was reported as 57\% [20], from reed as 65\% [50] and from rice straw as $64 \%$ [48]. Hence, it appears that the purely mechanical process employed in this study, i.e., PFI, renders MFC with higher crystallinity and less structural damage than the reported TEMPO routes. The same trend was noted by Jiménez-López et al. [43], who found less reduction in crystallinity for CNFs obtained from elm using only mechanical processes as compared to the TEMPO oxidation pretreatment prior to microfluidization. These authors mentioned that this fact may be linked, among other factors, to the oxidation of the internal cellulose crystallites. 


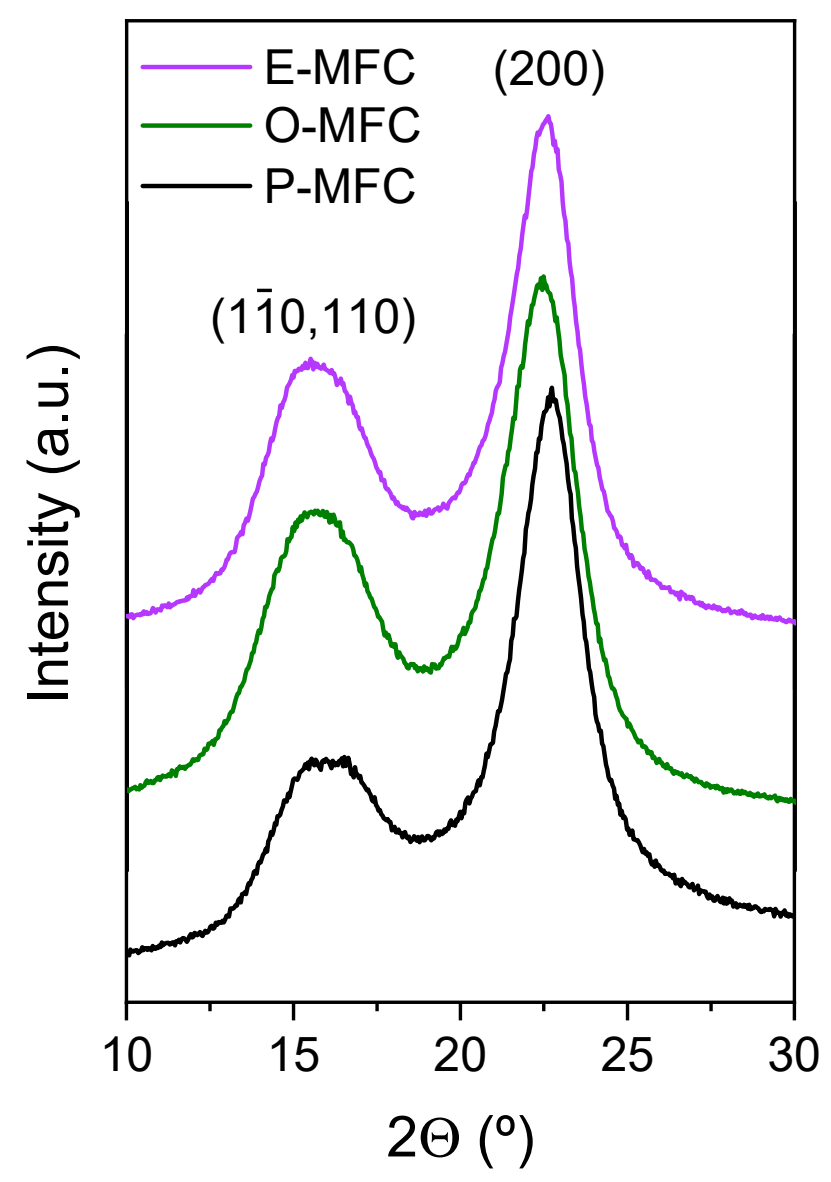

Figure 2. X-ray diffractograms of O-MFC, P-MFC and E-MFC, respectively.

\subsection{Film Properties}

3.3.1. Optical and Mechanical Properties

Films were obtained from MFC samples showing a density of $79.0 \mathrm{~g} \mathrm{~m}^{-2}$ and a thickness between 65.0 and $68.0 \mu \mathrm{m}$ (Table 4).

Table 4. Brightness, opacity, thickness, tensile index and elongation at break of MFC films.

\begin{tabular}{|c|c|c|c|c|c|}
\hline & $\begin{array}{l}\text { Brightness } \\
\text { (\%ISO) }\end{array}$ & $\begin{array}{l}\text { Opacity } \\
\text { (\%) }\end{array}$ & $\begin{array}{c}\text { Thickness } \\
(\mu \mathrm{m})\end{array}$ & $\begin{array}{l}\text { Tensile Index } \\
\left(\mathbf{k N ~ m ~ K g}{ }^{-1}\right)\end{array}$ & $\begin{array}{c}\text { Elongation at Break } \\
(\%)\end{array}$ \\
\hline O-MFC & $51.8 \pm 1.4$ & $74.0 \pm 0.6$ & $65.0 \pm 2.0$ & $150.0 \pm 0.01$ & $5.6 \pm 0.3$ \\
\hline P-MFC & $66.2 \pm 1.5$ & $71.0 \pm 3.1$ & $68.0 \pm 6.0$ & $130.0 \pm 0.02$ & $4.2 \pm 0.0$ \\
\hline E-MFC & $73.1 \pm 1.0$ & $73.1 \pm 0.8$ & $65.0 \pm 2.0$ & $150.0 \pm 0.01$ & $5.5 \pm 0.6$ \\
\hline
\end{tabular}

O-MFC: olive microfibrillated cellulose; P-MFC: poplar microfibrillated cellulose; E-MFC: eucalypt microfibrillated cellulose.

Optical properties (brightness and opacity) were evaluated (Table 4). The highest brightness value was observed for E-MFC film followed by P-MFC and O-MFC films. Taking into account the fact that all materials presented similar lignin contents (between $1.2 \%$ and $1.6 \%$ ), the high brightness of the E-MFC film could be related to its lower xylan content (19.1\%). In addition, xylan-lignin complexes are a source of residual poly-conjugates chromophores [51].

Compared with the initial raw materials $(61.5 \%, 73.2 \%$, and $78.2 \%$ brightness values for O-Pulp, P-Pulp and E-Pulp, respectively), a brightness decrease was observed for all MFC films after PFI refining and microfluidization (Table 4). This effect was previously reported by Spence et al. [46], describing a brightness reduction for hardwood and softwood pulps during the refining pretreatment with Valley beater followed by microfluidization. It is 
well known that, among other factors, the temperature reached during the refining stage may contribute to a decrease in the brightness of cellulosic pulps [52].

Regarding opacity, the three MFC films showed similarly high values (71.0-74.0\%), resulting in translucent films. Taking into account the low nanofibrillation yields of the MFC samples (11.3-13.3\%), a high presence of microscopic fibers, instead of nanofibers, remained in the suspension after microfluidization. This may produce high light scattering, which results in the high opacity of the MFC films. In this sense, Jiménez-López et al. [43] described a correlation between nanofibrilation yield and the transmittance (inversely related to opacity) observed for the resulting CNF films.

Mechanical properties (tensile index and elongation at break) of the MFC films were also characterized (Table 4). Tensile index values (130-150 kN m kg${ }^{-1}$ ) of the three MFC films were higher than the typical tensile indices reported for films from commercial Paper (range of 10-100 kN m kg${ }^{-1}$ ) [53]. It is known that microfluidization leads to nanofibers with higher specific surface area, which improves structure compaction and hydrogen bonding with the adjacent fibers, resulting in good mechanical properties. In this work, although low nanofibrilation yields were observed for the three samples, the micro- and nanofibrils contained in the three suspensions (as indicated by SEM images) could contribute to improving the tensile index of the resulting MFC films. Moreover, the drying treatment applied in this study during the preparation of the films (i.e., vacuum draining followed by hot-pressing) could also enhance the mechanical properties. In this regard, Österberg et al. [54] produced CNF films with twice the tensile strength by pressured filtration followed by an additional pressing step at about $100{ }^{\circ} \mathrm{C}$ and $1800 \mathrm{~Pa}$. They speculated that when the films are dried at high applied load and elevated temperature, denser films with a higher amount of bonds and fewer voids are produced. Finally, the high hemicellulose content reported in our samples can facilitate strong fiber-fiber bonding upon drying, contributing also to improve the mechanical properties. In this sense, Ferrer et al. [55] reported values of 86 and $95 \mathrm{kN} \mathrm{m} \mathrm{kg}^{-1}$ for films with CNF from bleached (lower hemicellulose content) and unbleached (higher hemicellulose content) pulps birch, respectively.

The elongation at break of the MFC films ranged from $4.2 \%$ for P-MFC to $5.5-5.6 \%$ for $\mathrm{O}-\mathrm{MFC}$ and E-MFC, which are typical values for micro- and nanofibrillated cellulose films $(1-10 \%)$ [36,56]. Similarly to the tensile index, the elongation at break is a property that is also improved by heat and load applied during film formation [54], as well as the high hemicellulose content [55].

It is worth mentioning the outstanding mechanical properties observed for these mechanically pretreated MCF films compared to those of TEMPO-mediated oxidized nanofibers (tensile index of $55-56 \mathrm{kN} \mathrm{m} \mathrm{Kg}^{-1}$ and elongation to break of 1.1-1.5\%) [43]. Despite the lower size of TEMPO-mediated oxidized nanofibers, the presence of carboxylate groups on the surface reduce the interfibril bonding since no hydrogen bonds are formed between hydroxyl groups and carboxylates. Furthermore, a lower degree of polymerization and crystallinity would contribute to lower mechanical strength.

\subsubsection{Wetting Properties}

Water vapor sorption isotherms were collected to characterize the wetting behavior of the three different MFC films (Figure 3). The isotherms are similar for all samples showing a maximum water sorption of $26-28 \mathrm{wt} \%$ at $95 \%$ relative humidity. This value is comparable to other MFC obtained by microfluidification [57]. At the low relative humidity range up to $30 \%$, it appears that P-MFC adsorbs slightly more water than the other two MFC films. This range is dominated by the formation of an initial water mono- and multilayer on the sorbent surface and therefore, is typically taken as a measure of a material's hydrophilicity [58]. 


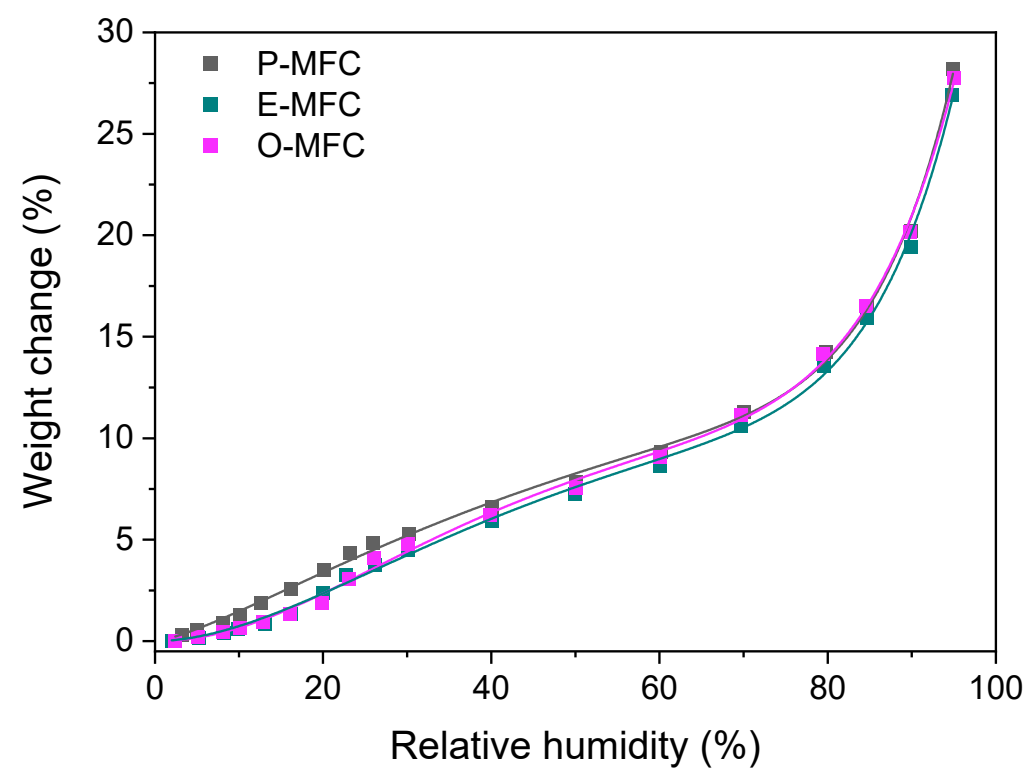

Figure 3. Water sorption isotherms of P-MFC, O-MFC and E-MFC films including the fitting curves according to Park's model.

More information on the wetting behavior can be extracted from modeling the water sorption isotherms. For cellulosic materials, these curves are commonly fitted with Park's model that describes the sorption process by an initial Langmuir-type adsorption, an intermediate adsorption following Henry's law and water clustering at high water activity [59]. This is due to the compositional and microstructural heterogeneity of natural fibers, which require a multi sorption mode model [60]. Thus, in Park's model, the quantity of adsorbed water $(\mathrm{Q})$ is calculated as follows:

$$
\mathrm{Q}=\frac{\mathrm{A}_{\mathrm{L}} \cdot \mathrm{b}_{\mathrm{L}} \cdot \mathrm{a}_{\mathrm{W}}^{1-\mathrm{c}}}{1+\mathrm{b}_{\mathrm{L}} \cdot \mathrm{a}_{\mathrm{W}}^{1-\mathrm{c}}}+\mathrm{K}_{\mathrm{H}} \cdot \mathrm{a}_{\mathrm{W}}+\mathrm{K}_{\mathrm{C}} \cdot \mathrm{a}_{\mathrm{W}}^{\mathrm{n}}
$$

where $\mathrm{Q}$ is the quantity of adsorbed water, $\mathrm{a}_{\mathrm{wW}}$ is the water activity, $\mathrm{A}_{\mathrm{L}}$ is the Langmuir capacity constant, $b_{\mathrm{L}}$ is the Langmuir affinity constant, $\mathrm{c}$ is a fitting coefficient, $\mathrm{K}_{\mathrm{H}}$ is Henry's solubility coefficient, $\mathrm{K}_{\mathrm{C}}$ is the equilibrium constant for the cluster formation and $\mathrm{n}$ is the mean number of water molecules per cluster.

The fitting Parameters in Table 5 corroborate that P-MFC is slightly more hydrophilic than the other two MFC films, as suggested by the higher Langmuir capacity constant $A_{L}$ and the mean cluster number $n$. On the other hand, O-MFC has the highest Henry's law constant, $\mathrm{K}_{\mathrm{H}}$, which is ascribed to the solubility of water within the cellulose fiber matrix interstices [60]. Hence, it may be speculated that O-MFC has a more open, accessible fiber matrix structure than the other MFC samples. Furthermore, the lower crystallinity index of this sample indicates a higher percentage of amorphous domains in which water can be adsorbed [45].

Table 5. Fitting Parameters of the water isotherms on MFC films according to Park's model.

\begin{tabular}{cccc}
\hline & O-MFC & E-MFC & P-MFC \\
\hline $\mathrm{A}_{\mathrm{L}}$ & 14 & 15 & 20 \\
$\mathrm{~K}_{\mathrm{H}}$ & 8.6 & 0.9 & 0.2 \\
$\mathrm{n}$ & 8.3 & 9.3 & 9.6 \\
$\mathrm{R} 2$ & 0.9976 & 0.9979 & 0.9981 \\
\hline
\end{tabular}

O-MFC: olive microfibrillated cellulose; P-MFC: poplar microfibrillated cellulose; E-MFC: eucalypt microfibrillated cellulose. 


\subsection{Approaching Several Applications of the MFC Samples}

The potential of fast-growing poplar and olive tree pruning as raw materials for the production of MFC has been demonstrated, obtaining samples with similar properties to MFC produced from a commercial eucalypt pulp. For that, PFI refining as pretreatment followed by microfluidization was employed, resulting in MFC samples with low fibrillation yields but high mechanical properties and low wettability. In spite of the low nanofibrillation yields obtained for the three samples, both the micro- and the nanofibrils contained in the three suspensions could be sufficient to improve the final mechanical properties of Paper and cardboard products [61,62]. This reinforcement effect is the result of the larger specific surface area of the micro- and nanofibers, which allow more interactions with the adjacent fibers in the fiber Paper matrix. In this sense, Salvador-Sanchez et al. [63] concluded that a high nanofibrillation yield is not necessary to improve mechanical Paper/cardboard properties. Then, they observed better mechanical properties (SCT index, tensile index, bursting index, and porosity) using microfibrillated cellulose obtained from softwood pulp by mechanical treatments (with low nanofibrillation yields between 5-19\%) as reinforcement agent compared to nanofibrillated cellulose produced by TEMPO-mediated oxidation pretreatment and homogenization (with higher nanofibrillation yield of 94\%). In the same way, Espinosa et al. [32] improved the mechanical properties (breaking length, Young's modulus, tear index, and burst index) of recycled Paperboard when MFC obtained from orange tree pruning by PFI refining and microfluidization (with nanofibrillation yield of $21 \%$ ) was used as a reinforcement additive. In addition, an analysis of the cost of increasing Paper properties such as breaking length reported by Delgado-Aguilar et al. [44] indicated that TEMPO-oxidized CNFs were more expensive than MFCs from mechanical pretreatment, the latter offering similar increases at lower prices. On the other hand, a possible reduction in aspect ratio (which could be related to a reduction in DP) in MFC samples could also be of special interest for their use as reinforcement agents in polymeric matrices [64].

In addition, the films produced from the three MFC samples showed interesting mechanical properties, one of the main requirements for Packaging applications [46]. The strength values of the resulting films are comparable to previous microfibrillated cellulose films with suitable mechanical properties (tensile index of $146 \mathrm{Nm} \mathrm{g}^{-1}$ and elongation at break of $8.6 \%$ ) for Packaging [53]. Together with the mechanical properties, barrier properties to gases such as oxygen are also important in Packaging applications [54]. The high crystallinity of the three mechanical MFC samples as well as the low wettability could also suggest good barrier properties of the resulting films. In this sense, Lagaron et al. [65] emphasized that high crystallinity of polymers improves barrier properties. Moreover, when the relative humidity increases, an important reduction in barrier properties was detected due to the adsorption of water and film swelling [66]. Then, a low wettability of films would prevent this decrease in barrier properties at high relative humidity. Finally, the high opacity determined in the three MFC films could lead to an improvement in the film barrier to UV and visible light, increasing the products shelf-life that can be altered by these radiations $[67,68]$.

Nevertheless, the hypotheses are only discussed with regard to their possible applications based on the properties described for the obtained MFC samples, which would have to be tested in future works.

\section{Conclusions}

This work has demonstrated the feasibility of obtaining microfibrillated cellulose (MFC) from fast-growing poplar and olive tree pruning using only mechanical treatments. All MFCs showed low fibrillation yield and high crystallinity, leading to films with high mechanical properties and low wettability. Moreover, these properties were very similar to those obtained with the reference raw material, eucalypt. Therefore, these MFCs and their respective films could be used as a reinforcing additive (both in Paper and board and in polymeric matrices due to their high mechanical properties) and in Packaging applications 
due not only to their good mechanical properties, but also to their high crystallinity and low wettability, which could give them good barrier properties.

Author Contributions: Conceptualization, D.I. and M.E.E.; methodology, D.I., R.M.-S., B.W., Ú.F. and M.E.E.; software, D.I., R.M.-S., B.W. and M.E.E.; validation, M.E.E., R.M.-S., B.W. and D.I.; formal analysis, D.I., R.M.-S., B.W. and M.E.E.; investigation, D.I., R.M.-S., B.W., Ú.F. and M.E.E.; resources, D.I., R.M.-S., B.W., Ú.F. and M.E.E.; data curation, D.I., R.M.-S., B.W. and M.E.E.; writingoriginal draft preparation, D.I., R.M.-S., B.W. and M.E.E.; writing-review and editing, D.I., R.M.-S., B.W. and M.E.E.; visualization, D.I., R.M.-S., B.W. and M.E.E.; supervision, M.E.E. and D.I.; project administration, M.E.E., B.W. and D.I.; funding acquisition, M.E.E., B.W. and D.I. All authors have read and agreed to the published version of the manuscript.

Funding: This research was funded by Comunidad de Madrid and MCIU/AEI/FEDER, EU via Projects SUSTEC-CM S2018/EMT-4348 and RTI2018-096080-B-C22, respectively. B.W. acknowledges financial support from MINECO (Spain) and FEDER (EU) (project MAT2015-71117-R) and from MICINN (Spain) for a JIN contract (PID2019-107022RJ-I00).

Institutional Review Board Statement: Not applicable.

Informed Consent Statement: Not applicable.

Data Availability Statement: Not applicable.

Acknowledgments: Universidad de Jaén and Silviculture and Forest Management Department (Forest Research Center, INIA, CSIC) are acknowledged for olive tree pruning and fast-growing poplar materials, respectively.

Conflicts of Interest: The authors declare no conflict of interest.

\section{References}

1. Van Renssen, S. A bioeconomy to fight climate change. Nat. Clim. Chang. 2014, 4, 951-953. [CrossRef]

2. Li, T.; Chen, C.; Brozena, A.H.; Zhu, J.Y.; Xu, L.; Driemeier, C.; Dai, J.; Rojas, O.J.; Isogai, A.; Wågberg, L.; et al. Developing fibrillated cellulose as a sustainable technological material. Nature 2021, 590, 47-56. [CrossRef] [PubMed]

3. De Souza Lima, M.M.; Borsali, R. Rodlike Cellulose Microcrystals: Structure, Properties, and Applications. Macromol. Rapid Commun. 2004, 25, 771-787. [CrossRef]

4. Rajinipriya, M.; Nagalakshmaiah, M.; Robert, M.; Elkoun, S. Importance of Agricultural and Industrial Waste in the Field of Nanocellulose and Recent Industrial Developments of Wood Based Nanocellulose: A Review. ACS Sustain. Chem. Eng. 2018, 6, 2807-2828. [CrossRef]

5. Nechyporchuk, O.; Belgacem, M.N.; Bras, J. Production of cellulose nanofibrils: A review of recent advances. Ind. Crop. Prod. 2016, 93, 2-25. [CrossRef]

6. Spence, K.L.; Venditti, R.A.; Rojas, O.J.; Habibi, Y.; Pawlak, J.J. A comparative study of energy consumption and physical properties of microfibrillated cellulose produced by different processing methods. Cellulose 2011, 18, 1097-1111. [CrossRef]

7. Michelin, M.; Gomes, D.G.; Romaní, A.; Polizeli, M.D.L.T.M.; Teixeira, J.A. Nanocellulose Production: Exploring the Enzymatic Route and Residues of Pulp and Paper Industry. Molecules 2020, 25, 3411. [CrossRef]

8. Saito, T.; Nishiyama, Y.; Putaux, J.-L.; Vignon, M.; Isogai, A. Homogeneous Suspensions of Individualized Microfibrils from TEMPO-Catalyzed Oxidation of Native Cellulose. Biomacromolecules 2006, 7, 1687-1691. [CrossRef]

9. Taipale, T.; Österberg, M.; Nykänen, A.; Ruokolainen, J.; Laine, J. Effect of microfibrillated cellulose and fines on the drainage of kraft pulp suspension and Paper strength. Cellulose 2010, 17, 1005-1020. [CrossRef]

10. Chinga-Carrasco, G.; Yu, Y.; Diserud, O. Quantitative Electron Microscopy of Cellulose Nanofibril Structures from Eucalyptus and Pinus radiata Kraft Pulp Fibers. Microsc. Microanal. 2011, 17, 563-571. [CrossRef]

11. Kandhola, G.; Djioleu, A.; Rajan, K.; Labbé, N.; Sakon, J.; Carrier, D.J.; Kim, J.-W. Maximizing production of cellulose nanocrystals and nanofibers from pre-extracted loblolly pine kraft pulp: A response surface approach. Bioresour. Bioprocess. 2020, 7, 19. [CrossRef]

12. Zalesny, R.S.; Donner, D.M.; Coyle, D.R.; Headlee, W.L. An approach for siting poplar energy production systems to increase productivity and associated ecosystem services. For. Ecol. Manag. 2012, 284, 45-58. [CrossRef]

13. Weng, J.; Jia, L.; Wang, Y.; Sun, S.; Tang, X.; Zhou, Z.; Kohse-Höinghaus, K.; Qi, F. Pyrolysis study of poplar biomass by tunable synchrotron vacuum ultraviolet photoionization mass spectrometry. Proc. Combust. Inst. 2013, 34, 2347-2354. [CrossRef]

14. Sixto, H.; Cañellas, I.; van Arendonk, J.; Ciria, P.; Camps, F.; Sánchez, M.; Sánchez-González, M. Growth potential of different species and genotypes for biomass production in short rotation in Mediterranean environments. For. Ecol. Manag. 2015, 354, 291-299. [CrossRef]

15. Romero-García, J.M.; Niño, L.; Martínez-Patiño, C.; Álvarez, C.; Castro, E.; Negro, M.J. Biorefinery based on olive biomass. State of the art and future trends. Bioresour. Technol. 2014, 159, 421-432. [CrossRef] 
16. Jiménez-López, L.; Martín-Sampedro, R.; Eugenio, M.E.; Santos, J.I.; Sixto, H.; Cañellas, I.; Ibarra, D. Co-production of soluble sugars and lignin from short rotation white poplar and black locust crops. Wood Sci. Technol. 2020, 54, 1617-1643. [CrossRef]

17. Martín-Sampedro, R.; Rodríguez, A.; Requejo, A.; Eugenio, M.E. Improvement of TCF bleaching of olive tree pruning residue pulp by addition of a laccase and/or xylanase pre-treatment. BioResources 2012, 7, 1488-1503. [CrossRef]

18. Martín-Sampedro, R.; Santos, J.I.; Fillat, Ú.; Wicklein, B.; Eugenio, M.E.; Ibarra, D. Characterization of lignins from Populus alba L. generated as by-products in different transformation processes: Kraft pulping, organosolv and acid hydrolysis. Int. J. Biol. Macromol. 2019, 126, 18-29. [CrossRef]

19. Oliva, J.M.; Negro, M.J.; Álvarez, C.; Manzanares, P.; Moreno, A.D. Fermentation strategies for the efficient use of olive tree pruning biomass from a flexible biorefinery approach. Fuel 2020, 277, 118171. [CrossRef]

20. Fillat, UU.; Wicklein, B.; Martín-Sampedro, R.; Ibarra, D.; Ruiz-Hitzky, E.; Valencia, C.; Sarrión, A.; Castro, E.; Eugenio, M.E. Assessing cellulose nanofiber production from olive tree pruning residue. Carbohydr. Polym. 2018, 179, 252-261. [CrossRef]

21. Zhao, G.; Du, J.; Chen, W.; Pan, M.; Chen, D. Preparation and thermostability of cellulose nanocrystals and nanofibrils from two sources of biomass: Rice straw and poplar wood. Cellulose 2019, 26, 8625-8643. [CrossRef]

22. Sánchez-Gutiérrez, M.; Espinosa, E.; Bascón-Villegas, I.; Pérez-Rodríguez, F.; Carrasco, E.; Rodríguez, A. Production of Cellulose Nanofibers from Olive Tree Harvest-A Residue with Wide Applications. Agronomy 2020, 10, 696. [CrossRef]

23. Kang, K.-Y.; Jo, B.-M.; Oh, J.-S.; Mansfield, S.D. The effects of biopulping on chemical and energy consumptionduring Kraft pulping of hybrid poplar. Wood Fiber Sci. 2003, 35, 594-600.

24. Ibarra, D.; Camarero, S.; Romero, J.; Martínez, M.J.; Martínez, A.T. Integrating laccase-mediator treatment into an industrial-type sequence for totally chlorine-free bleaching of eucalypt kraft pulp. J. Chem. Technol. Biotechnol. 2006, 81, 1159-1165. [CrossRef]

25. Swerin, A.; Odberg, L.; Lindström, T. Deswelling of hardwood kraft pulp fibers by cationic polymers. Nord. Pulp Pap. Res. J. 1990, 5, 188-196. [CrossRef]

26. Tenhunen, T.-M.; Peresin, M.S.; Penttilä, P.A.; Pere, J.; Serimaa, R.; Tammelin, T. Significance of xylan on the stability and water interactions of cellulosic nanofibrils. React. Funct. Polym. 2014, 85, 157-166. [CrossRef]

27. Missoum, K.; Belgacem, M.N.; Bras, J. Nanofibrillated Cellulose Surface Modification: A Review. Materials 2013, 6, 1745-1766. [CrossRef]

28. NRLE TP-510-42618-Determination of structural carbohydrates and lignin in biomass. In Laboratory Analytical Procedure; National Renewable Energy Laboratory: Golden, CO, USA, 2011.

29. Kasaai, M.R. Comparison of various solvents for determination of intrinsic viscosity and viscometric constants for cellulose. J. Appl. Polym. Sci. 2002, 86, 2189-2193. [CrossRef]

30. Besbes, I.; Alila, S.; Boufi, S. Nanofibrillated cellulose from TEMPO-oxidized eucalyptus fibres: Effect of the carboxyl content. Carbohydr. Polym. 2011, 84, 975-983. [CrossRef]

31. Cheng, Q.; Wang, J.; Mcneel, J.; Jacobson, P. Water retention value measurements of cellulosic materials using a centrifuge technique. Bioresources 2010, 5, 1945-1954. [CrossRef]

32. Espinosa, E.; Arrebola, R.I.; Bascón-Villegas, I.; Sánchez-Gutiérrez, M.; Domínguez-Robles, J.; Rodríguez, A. Industrial application of orange tree nanocellulose as Papermaking reinforcement agent. Cellulose 2020, 27, 10781-10797. [CrossRef]

33. Fodil Cherif, M.; Trache, D.; Brosse, N.; Benaliouche, F.; Tarchoun, A.F. Comparison of the Physicochemical Properties and Thermal Stability of Organosolv and Kraft Lignins from Hardwood and Softwood Biomass for Their Potential Valorization. Waste Biomass Valorization 2020, 11, 6541-6553. [CrossRef]

34. Chaker, A.; Alila, S.; Mutjé, P.; Vilar, M.R.; Boufi, S. Key role of the hemicellulose content and the cell morphology on the nanofibrillation effectiveness of cellulose pulps. Cellulose 2013, 20, 2863-2875. [CrossRef]

35. Arola, S.; Malho, J.; Laaksonen, P.; Lille, M.; Linder, M.B. The role of hemicellulose in nanofibrillated cellulose networks. Soft Matter 2013, 9, 1319-1326. [CrossRef]

36. Rojo, E.; Peresin, M.S.; Sampson, W.W.; Hoeger, I.C.; Vartiainen, J.; Laine, J.; Rojas, O.J. Comprehensive elucidation of the effect of residual lignin on the physical, barrier, mechanical and surface properties of nanocellulose films. Green Chem. 2015, 17, 1853-1866. [CrossRef]

37. Fall, A.B.; Burman, A.; Wågberg, L. Cellulosic nanofibrils from eucalyptus, acacia and pine fibers. Nord. Pulp Pap. Res. J. 2014, 29, 176-184. [CrossRef]

38. Solala, I.; Iglesias, M.C.; Peresin, M.S. On the potential of lignin-containing cellulose nanofibrils (LCNFs): A review on properties and applications. Cellulose 2020, 27, 1853-1877. [CrossRef]

39. Rajan, K.; Djioleu, A.; Kandhola, G.; Labbé, N.; Sakon, J.; Carrier, D.J.; Kim, J.-W. Investigating the effects of hemicellulose pre-extraction on the production and characterization of loblolly pine nanocellulose. Cellulose 2020, 27, 3693-3706. [CrossRef]

40. Solala, I.; Volperts, A.; Andersone, A.; Dizhbite, T.; Mironova-Ulmane, N.; Vehniäinen, A.; Pere, J.; Vuorinen, T. Mechanoradical formation and its effects on birch kraft pulp during the preparation of nanofibrillated cellulose with Masuko refining. Holzforschung 2012, 66, 477-483. [CrossRef]

41. Chinga-Carrasco, G. Cellulose fibres, nanofibrils and microfibrils: The morphological sequence of MFC components from a plant physiology and fibre technology point of view. Nanoscale Res. Lett. 2011, 6, 417. [CrossRef]

42. Siró, I.; Plackett, D.; Hedenqvist, M.; Ankerfors, M.; Lindström, T. Highly transparent films from carboxymethylated microfibrillated cellulose: The effect of multiple homogenization steps on key properties. J. Appl. Polym. Sci. 2011, 119, 2652-2660. [CrossRef] 
43. Jiménez-López, L.; Eugenio, M.E.; Ibarra, D.; Darder, M.; Martín, J.A.; Martín-Sampedro, R. Cellulose nanofibers from a dutch elm disease-resistant ulmus minor clone. Polymers 2020, 12, 2450. [CrossRef] [PubMed]

44. Delgado-Aguilar, M.; González Tovar, I.; Tarrés, Q.; Alcalá, M.; Pèlach, M.À.; Mutjé, P. Approaching a Low-Cost Production of Cellulose Nanofibers for Papermaking Applications. BioResources 2015, 10, 5345-5355. [CrossRef]

45. Meriçer, Ç.; Minelli, M.; Giacinti Baschetti, M.; Lindström, T. Water sorption in microfibrillated cellulose (MFC): The effect of temperature and pretreatment. Carbohydr. Polym. 2017, 174, 1201-1212. [CrossRef] [PubMed]

46. Spence, K.L.; Venditti, R.A.; Habibi, Y.; Rojas, O.J.; Pawlak, J.J. The effect of chemical composition on microfibrillar cellulose films from wood pulps: Mechanical processing and physical properties. Bioresour. Technol. 2010, 101, 5961-5968. [CrossRef] [PubMed]

47. French, A.D.; Santiago Cintrón, M. Cellulose polymorphy, crystallite size, and the Segal Crystallinity Index. Cellulose 2013, 20, 583-588. [CrossRef]

48. Jiang, F.; Hsieh, Y.-L. Chemically and mechanically isolated nanocellulose and their self-assembled structures. Carbohydr. Polym. 2013, 95, 32-40. [CrossRef] [PubMed]

49. Liu, C.; Li, B.; Du, H.; Lv, D.; Zhang, Y.; Yu, G.; Mu, X.; Peng, H. Properties of nanocellulose isolated from corncob residue using sulfuric acid, formic acid, oxidative and mechanical methods. Carbohydr. Polym. 2016, 151, 716-724. [CrossRef] [PubMed]

50. Barbash, V.A.; Yashchenko, O.V.; Gondovska, A.S.; Deykun, I.M. Preparation and characterization of nanocellulose obtained by TEMPO-mediated oxidation of organosolv pulp from reed stalks. Appl. Nanosci. 2021, 1-14. [CrossRef]

51. Loureiro, P.E.G.; Sousa, J.I.T.; Carvalho, M.G.V.S.; Evtuguin, D.V. Contribution of xylan to the brightness development and stability in the final ECF bleaching of eucalypt (Eucalyptus globulus Labill.) kraft pulp. Holzforschung 2013, 67, 497-503. [CrossRef]

52. García-Fuentevilla, L.L.; Martin-Sampedro, R.; Domínguez, P.; Villar, J.C.; Eugenio, M.E. Refining and urea pretreatments to enhance biobleaching of eucalyptus kraft pulp. BioResources 2013, 8, 4849-4863. [CrossRef]

53. Syverud, K.; Stenius, P. Strength and barrier properties of MFC films. Cellulose 2009, 16, 75-85. [CrossRef]

54. Österberg, M.; Vartiainen, J.; Lucenius, J.; Hippi, U.; Seppälä, J.; Serimaa, R.; Laine, J. A Fast Method to Produce Strong NFC Films as a Platform for Barrier and Functional Materials. ACS Appl. Mater. Interfaces 2013, 5, 4640-4647. [CrossRef] [PubMed]

55. Ferrer, A.; Quintana, E.; Filpponen, I.; Solala, I.; Vidal, T.; Rodríguez, A.; Laine, J.; Rojas, O.J. Effect of residual lignin and heteropolysaccharides in nanofibrillar cellulose and nanopaper from wood fibers. Cellulose 2012, 19, 2179-2193. [CrossRef]

56. Nobuta, K.; Teramura, H.; Ito, H.; Hongo, C.; Kawaguchi, H.; Ogino, C.; Kondo, A.; Nishino, T. Characterization of cellulose nanofiber sheets from different refining processes. Cellulose 2016, 23, 403-414. [CrossRef]

57. Belbekhouche, S.; Bras, J.; Siqueira, G.; Chappey, C.; Lebrun, L.; Khelifi, B.; Marais, S.; Dufresne, A. Water sorption behavior and gas barrier properties of cellulose whiskers and microfibrils films. Carbohydr. Polym. 2011, 83, 1740-1748. [CrossRef]

58. Hill, C.A.S.; Norton, A.; Newman, G. The water vapor sorption behavior of natural fibers. J. Appl. Polym. Sci. 2009, 112, 1524-1537. [CrossRef]

59. Park, G.S. Transport Principles—Solution, Diffusion and Permeation in Polymer Membranes. In Synthetic Membranes: Science, Engineering and Applications; Springer: Dordrecht, The Netherlands, 1986.

60. Bessadok, A.; Marais, S.; Roudesli, S.; Lixon, C.; Métayer, M. Influence of chemical modifications on water-sorption and mechanical properties of Agave fibres. Compos. Part A Appl. Sci. Manuf. 2008, 39, 29-45. [CrossRef]

61. Delgado-Aguilar, M.; González, I.; Pèlach, M.A.; De La Fuente, E.; Negro, C.; Mutjé, P. Improvement of deinked old newspaper/old magazine pulp suspensions by means of nanofibrillated cellulose addition. Cellulose 2015, 22, 789-802. [CrossRef]

62. Delgado-Aguilar, M.; Tarrés, Q.; Pèlach, M.À.; Mutjé, P.; Fullana-i-Palmer, P. Are Cellulose Nanofibers a Solution for a More Circular Economy of Paper Products? Environ. Sci. Technol. 2015, 49, 12206-12213. [CrossRef]

63. Sanchez-Salvador, J.L.; Balea, A.; Monte, M.C.; Negro, C.; Miller, M.; Olson, J.; Blanco, A. Comparison of Mechanical and Chemical Nanocellulose as Additives to Reinforce Recycled Cardboard. Sci. Rep. 2020, 10, 3778. [CrossRef] [PubMed]

64. Zimmermann, T.; Bordeanu, N.; Strub, E. Properties of nanofibrillated cellulose from different raw materials and its reinforcement potential. Carbohydr. Polym. 2010, 79, 1086-1093. [CrossRef]

65. Lagaron, J.M.; Catalá, R.; Gavara, R. Structural characteristics defining high barrier properties in polymeric materials. Mater. Sci. Technol. 2004, 20, 1-7. [CrossRef]

66. Lavoine, N.; Desloges, I.; Dufresne, A.; Bras, J. Microfibrillated cellulose-Its barrier properties and applications in cellulosic materials: A review. Carbohydr. Polym. 2012, 90, 735-764. [CrossRef]

67. Tibolla, H.; Pelissari, F.M.; Martins, J.T.; Lanzoni, E.M.; Vicente, A.A.; Menegalli, F.C.; Cunha, R.L. Banana starch nanocomposite with cellulose nanofibers isolated from banana peel by enzymatic treatment: In vitro cytotoxicity assessment. Carbohydr. Polym. 2019, 207, 169-179. [CrossRef] [PubMed]

68. Bardet, R.; Belgacem, M.N.; Bras, J. Different strategies for obtaining high opacity films of MFC with TiO 2 pigments. Cellulose 2013, 20, 3025-3037. [CrossRef] 